\title{
UMA ANÁLISE DA MOBILIDADE DE TRABALHADORES QUALIFICADOS DA INDÚSTRIA DE TRANSFORMAÇÃO BRASILEIRA $^{(*)(*)}$
}

\author{
Juliana Gonçalves Taveira*** \\ Eduardo Gonçalves ${ }^{* * * *}$ \\ Ricardo da Silva Freguglia ${ }^{* * * * * *}$
}

RESUMO: Este artigo procura analisar, de forma exploratória, os migrantes qualificados que saem de algum município do Estado de São Paulo, entre os anos de 1999 a 2002, quanto às suas características pessoais, como: gênero, idade e escolaridade; as características municipais, como: tamanho da cidade, bem como a intensidade tecnológica setorial. Para tal, é construído um banco de dados a partir da RAIS-Migra do Ministério do Trabalho e Emprego (MTE) que possui a vantagem de acompanhar longitudinalmente os trabalhadores do mercado formal de trabalho. Dentre os principais resultados, verifica-se que a mobilidade ocorre, em sua maioria, para trabalhadores do sexo masculino, mais jovens e com maior escolaridade, além de haver relevante migração para cidades de médio e pequeno porte e de migração intragrupo de acordo com a intensidade tecnológica.

PALAVRAS-CHAVE: trabalhadores qualificados; mobilidade; São Paulo.

\footnotetext{
* Os autores agradecem o apoio do Ministério do Trabalho e Emprego e do CNPq.

** Artigo recebido 24/11/2010 e aprovado 01/09/2011.

*** Mestranda em economia aplicada da Universidade Federal de Juiz de Fora. Contato: julianagtaveira@ gmail.com.

${ }_{* * * \star}$ Doutor em Economia Regional e Urbana pelo CEDEPLAR/UFMG e professor adjunto da Faculdade de Economia da Universidade Federal de Juiz de Fora. Contato: eduardo.goncalves@uff.edu.br.

***** Doutor em Economia pelo IPE/USP e professor adjunto da Faculdade de Economia da Universidade Federal de Juiz de Fora. Contato: ricardo.freguglia@ufff.edu.br.
} 


\section{AN ANALYSIS OF SKILLED WORKERS IN THE BRAZILIAN MANUFACTURING INDUSTRY}

ABSTRACT: This paper undertakes an exploratory analysis of the skilled workers who migrates from some municipality of the state of São Paulo to another municipality between 1999 and 2002. We analyzes this migration in terms of personal characteristics - such as gender, age and educational level -, urban aspects - such as the size of city -, as well as the technological intensity of sector. To achieve this objective, we use a database from Labor Ministry of Brazil (RAIS-Migra) that has the advantage of following the same workers in the formal labor market. Our main results reveal that the majority of migrant workers are male, young and highly educated. Besides, there is a relevant mobility level of workers towards medium-sized and small cities and the migration tends to occur more frequently into similar sectors in terms of technological intensity.

KEY WORDS: skilled workers; mobility; São Paulo.

JEL: J61; O15; R10.

\section{INTRODUÇÃO}

A mobilidade de trabalhadores qualificados se destaca como uma das principais formas de difusão de conhecimento científico e tecnológico (Mukkala, 2005). Tal fato se deve a tais profissionais terem um tipo de conhecimento que só pode ser transmitido via contato direto, o conhecimento tácito. O capital humano determina quanto do potencial de inovação se transforma em práticas tecnológicas e inovadoras (Laafia e Stimpson, 2001).

Níveis relevantes de mobilidade ${ }^{1}$ de pessoas altamente educadas asseguram o nível de inovação regional e garantem seu desenvolvimento econômico (Graversen e Friis-Jensen, 2001). A difusão de conhecimento científico contribui para maiores níveis de atividades empreendedoras e de produtividade, e se distribui regionalmente, principalmente através da migração, em especial de trabalhadores qualificados.

\footnotetext{
${ }^{1}$ Os termos migração e mobilidade serão considerados equivalentes neste trabalho. Uma definição se refere à migração como a transferência de uma pessoa de um espaço geográfico para outro com a intenção de ficar no destino por um tempo determinado, pelo critério das Nações Unidas, um ano. Em relação à mobilidade, esta não está vinculada a uma mudança geográfica. Alguns autores a definem como o número de trabalhadores que mudaram de local de trabalho (Graversen e Friis-Jensen, 2001).
} 
Através dela, regiões terão acesso a conhecimentos tecnológicos que as inserirão nos sistemas de inovação que, por outro meio, talvez não tivessem.

Segundo a literatura sobre migração, o trabalhador migrante se destaca por ser mais motivado e habilidoso que os demais trabalhadores (Chiswick, 1978). Isso pode ajudar a explicar um maior crescimento das regiões com convergência de migrantes e migrantes qualificados. Como o conhecimento tecnológico difunde-se principalmente por meio de mobilidade de profissionais qualificados (Feldman, 1999), a compreensão do comportamento dessa mobilidade torna-se relevante, uma vez que permite caracterizar o mercado de trabalho de uma dada região e seu nível de desenvolvimento. Isso porque o potencial de transbordamento de conhecimento tecnológico pode ser um meio de tornar acessível a outras regiões um conhecimento importante para fins de desenvolvimento regional.

No Brasil, observa-se uma concentração de atividades industriais e tecnológicas na região Sudeste. Dentro dela, o estado de São Paulo concentra a maior parte dos profissionais qualificados e aqueles vinculados às atividades intensivas em conhecimento (Diniz e Gonçalves, 2001). Freguglia e Menezes-Filho (2007), em um estudo que realça o papel das habilidades não observadas como causa dos diferenciais salariais destacam São Paulo como concentrador de indivíduos com alta habilidade.

Tendo em vista a concentração de profissionais qualificados e de inovação no estado de São Paulo em relação ao restante do país (Diniz e Gonçalves, 2001), torna-se representativo analisar a mobilidade de trabalhadores nessa região. Nesse contexto, é preciso abordar alguns determinantes da mobilidade de trabalhadores qualificados, considerados relevantes pela literatura nacional e internacional, a fim de caracterizar a extensão espacial do potencial de transbordamento de conhecimento a partir dessa região, e suas consequências sobre o desenvolvimento regional.

O presente trabalho tem por objetivo avaliar as características dos trabalhadores da indústria que mudam de município de trabalho a partir do estado de São Paulo, em relação a características pessoais, municipais, assim como as características dos trabalhadores qualificados e em setores intensivos em tecnologia. Para isso, definem-se como intensivos em tecnologia os setores que possuem alta e média-alta relação entre gastos em pesquisa e desenvolvimento e valor agregado na estrutura industrial (Furtado e Carvalho, 2005). Ao focar na migração de pessoas qualificadas de setores intensivos em tecnologia, busca-se retratar o processo de difusão de conhecimento tecnológico, que determina alterações do estoque regional de capital humano e o desenvolvimento regional.

Este artigo está organizado em quatro seções além desta introdução. A primeira seção faz uma breve revisão da literatura nacional e internacional a respeito do tema, apresentando evidências empíricas. A segunda apresenta a metodologia utilizada, 
e a terceira descreve os resultados encontrados para o caso de São Paulo. Por fim, apresenta-se uma conclusão destacando os principais pontos do trabalho.

\section{REVISÃO DA LITERATURA}

\subsection{A MOBILIDADE DE TRABALHADORES E O SEU PAPEL NA DIFUSÃO DE CONHECIMENTO TECNOLÓGICO}

A mobilidade de trabalhadores pode ser considerada importante para a difusão e fluxo de conhecimento entre as firmas (Dahl, 2004). Ela se destaca como importante meio de difusão de conhecimento entre as regiões, e pode levar a mudanças significativas nos estoques regionais de capital humano. O capital humano, dessa forma, se torna fator-chave no desenvolvimento regional e na competitividade, sendo a maioria dos estudos unânimes ao concluir que a propagação de conhecimento é importante e está, altamente, ligada à concentração localizada de conhecimento (Mukkala, 2005).

A migração inter-regional de trabalhadores qualificados determina a difusão de conhecimento tecnológico entre firmas e regiões, principal forma de ocorrência dos transbordamentos de conhecimento (Feldman, 1999). Ao considerar que a mão de obra qualificada não migra entre firmas e regiões, algumas destas poderiam ter seu crescimento econômico comprometido (Dahl, 2004).

Migrantes são considerados auto selecionados em relação aos indivíduos que optam por permanecer em seu lugar de origem, ou seja, seriam em média, mais ambiciosos, empreendedores (mais habilidosos) (Chiswick e Hollifield, 1999). Tal fato ajudaria a explicar maior crescimento das regiões com maior número de migrantes qualificados e o aumento do salário do migrante em relação aos nativos. Em estudo recente, Freguglia e Menezes-Filho (2007) apontam ainda a importância das habilidades individuais não observadas como fator determinante dos diferenciais salariais no mercado de trabalho formal entre os estados brasileiros.

A migração pode ser entendida como um investimento em capital humano. Ao migrar, inicialmente, o indivíduo possui gastos monetários e não monetários e obterá um retorno do investimento com o decorrer do tempo (Sjaastad, 1962). Dessa forma, a decisão de migrar se dará apenas quando houver chances de se recuperar os custos monetários e/ou não monetários com a migração.

Evidências empíricas indicam que a probabilidade de migração é sensível aos diferenciais de renda entre as regiões e têm relação negativa com a distância entre destino e origem (Borjas, 1996). Lucas (2001) destaca a preferência pelas migrações de curta distância. Zimmermann (2004) também considera que os riscos e custos de migrar devem aumentar com a distância entre origem e destino do migrante. Mi- 
grações de longa distância incorrem em custos psicológicos e de obtenção de informação do destino maiores do que as de curta distância, além disso, migrações para lugares próximos à origem facilitam uma migração de retorno, em caso de crise.

A existência de remessas de dinheiro - bem como suas magnitudes - enviadas às cidades de origem denota, ainda, uma ligação entre os migrantes e sua cidade natal (Korinnek e Entwisle, 2005). A decisão de migrar responde substancialmente a diferenças regionais de riqueza, de salários, de taxas de desemprego, de custo de vida (Zimmermann, 2004). Fatores ligados à idade, existência de filhos, de cônjuge ou relação com a família também influenciam na mobilidade geográfica do indivíduo (Dahl, 2004).

Borjas (1996) apresenta duas causas para uma correlação positiva entre a qualificação e probabilidade de migração: 1) tais trabalhadores adquirem informações sobre outros mercados de trabalho de forma mais eficiente, incorrendo em custos de migração menores; 2) esses trabalhadores possuiriam maiores alternativas de emprego no destino.

Já a correlação negativa entre o envelhecimento do trabalhador e sua probabilidade de migração pode ser justificada pelo fato dos trabalhadores mais velhos possuírem um período de tempo menor para obter os retornos do investimento com a migração (Borjas, 1996).

Dependendo das características regionais e dos tipos de migrantes que cada região atrai, ou perde, ela se beneficiará, ou não, da migração (Golgher, 2008). A mobilidade geográfica de trabalhadores é encarada como um importante instrumento de promoção de ajuste de diferenças de capital humano entre regiões e do crescimento econômico (Zimmermann, 2004).

O efeito da migração de trabalhadores qualificados pode ser adverso ou favorável para o nativo. Se por um lado Borjas (2005) aponta que um aumento da oferta de doutores, em um determinado mercado e período, reduzem o ganho de doutores nativos em $3 \%$, por outro, afirma que a entrada desses no mercado pode estimular a contratação de trabalhadores, migrantes ou não, com qualificações complementares.

Um efeito regional da migração constitui a fuga de cérebros, fenômeno em que ocorre a emigração de pessoas relativamente mais qualificadas de regiões subdesenvolvidas para regiões desenvolvidas. Segundo Beine et al. (2008), na fuga de cérebros, aparentemente, as perdas seriam comparativamente menores que os ganhos, havendo assim um saldo total positivo para os países em desenvolvimento, que através desse fenômeno estariam tendo sua população de trabalhadores qualificados aumentada. Dessa forma, tal fenômeno estaria contribuindo para o desenvolvimento desses países.

Em relação às consequências sofridas pelo migrante, Golgher (2008) afirma que os ganhos na maioria dos casos são positivos, mas destaca a dificuldade da fase de adaptação. Tal fato está, intimamente, ligado à migração de retorno. 


\subsection{EVIDÊNCIAS EMPÍRICAS INTERNACIONAIS DA MOBILIDADE DE TRABALHADORES}

Em seu estudo sobre a Finlândia, Mukkala (2005) comprova empiricamente que a propensão à migração é maior em trabalhadores qualificados dos setores de alta tecnologia se comparados com os outros trabalhadores. Tal fato contribui para a transferência efetiva de conhecimento entre firmas e regiões.

Kulu e Billari (2004), ao estudarem a Estônia, demonstram que tanto fatores pessoais como regionais influenciam a migração dos indivíduos. Os autores perceberam grande importância da renda, desejos e crenças dos indivíduos no seu comportamento migratório. A idade e as relações interpessoais, assim como sexo, são determinantes da probabilidade de migração.

Pessoas pertencentes a minorias étnicas tendem a migrar pouco e para regiões étnicas compatíveis, o que demonstra uma característica concentradora deste grupo (Kulu e Billari, 2004). A maioria dos migrantes se muda dentro de um contexto étnico, resultando em formação de clusters na região de destino (Zimmermann, 2004).

As características pessoais que mais influenciam na decisão de migração são idade e nível educacional, tendo a primeira correlação negativa e a segunda positiva. Pessoas com maior nível educacional tenderiam a migrar mais, visto que uma maior educação incorre em menores riscos, devido a uma maior capacidade de coletar e processar as informações (Zimmermann, 2004). Os trabalhos de Pekkala (2003), Mukkala (2005) e Bover e Arellano (2002) confirmam essa relação positiva entre qualificação e migração. Nakosteen e Westerlund (2004), analisando a Suécia, apontam que a probabilidade de migração diminui com a idade. $\mathrm{O}$ mesmo se observa nos casos da Estônia e da Noruega (Kulu e Billari, 2004; Stambol, 2003).

$\mathrm{Na}$ Estônia, foi observado que uma maior dispersão dos locais de trabalho mais desejados promove uma maior mobilidade das pessoas com nível educacional maior (Kulu e Billari, 2004). O nível educacional dos migrantes é, significativamente, maior se comparados com os não migrantes (Stambol, 2003).

Jauhiainen (2008) destaca que os trabalhadores mais educados tendem a se concentrar nas cidades grandes, o que contribui para a concentração de capital humano nessas regiões. Tal fato ocorreria, pois nessas cidades os retornos de seu investimento em capital humano são maiores, além de as pessoas adquirirem conhecimento mais facilmente.

Jackman e Savouri (1992), ao analisar o Reino Unido, constataram que elevados preços relativos de casas, utilizado como proxy de custo de vida, influenciam, positivamente, a emigração e, negativamente, a imigração. Os autores destacam ainda que a existência de casa própria na cidade de origem seria um fator que influenciaria negativamente a decisão de migrar. Bover e Arellano (2002) ao estudarem a Espanha, perceberam que as pessoas se dirigiam para as cidades pequenas e médias onde o custo de vida é menor. 
Lucas (2001), ao estudar a migração internacional, percebe que esta é maior quanto menor a distância entre os países. Ele afirma que a migração para lugares mais distantes incorre em maiores custos psicológicos, além disso, os migrantes, por deixarem ativos ou por possuírem familiares em sua cidade de origem, têm a necessidade de fazer visitas frequentes a ela, o que os incentiva a não migrar para muito longe. Outro ponto ressaltado seria que migrações de curta distância permitem retornos mais fáceis em caso de crise.

A decisão de migrar está diretamente relacionada com as condições do mercado de trabalho (Debelle e Vickery, 1998). Estudos da Suécia (Nakosteen e Westerlund, 2004), do Reino Unido (Jackman e Savouri, 1992), da Espanha (Bover e Arellano, 2002) e da Austrália (Debelle e Vickery, 1998) confirmam uma correlação positiva entre condições de mercado favoráveis no destino e a migração. Contudo observa-se que, mesmo quando a taxa de desemprego em uma região é maior do que nas outras, se o nível salarial também o for, o trabalhador ainda assim preferirá tal região se esse maior salário compensar a diminuição da probabilidade de se arrumar um emprego (Debelle e Vickery, 1998).

Ao observar diferenciais salariais entre migrantes e não migrantes, na Dinamarca, verificou-se que os primeiros têm um aumento de $30 \%$ em sua renda devido à mudança de emprego em relação aos que não migraram (Dahl, 2004). Na Noruega, Stambol (2003) descobre que os migrantes apresentam salários superiores aos dos não migrantes, e salários ainda maiores se comparados aos trabalhadores nativos.

$\mathrm{Na}$ Bélgica homens tenderiam a migrar mais que as mulheres (Viszt et al., 2001). O que também é observado na Dinamarca, onde o autor percebeu que homens têm probabilidade de migrar 35\% maior do que as mulheres (Dahl, 2004). Pekkala (2003) percebe que um indivíduo do sexo feminino, chefe da família, com família grande, ou com casa própria, está mais ligado à sua cidade de origem, o que diminui as chances de migração.

Nos países nórdicos, os autores perceberam que a formação de família representa um vínculo do trabalhador a sua origem. Destacaram ainda que trabalhadores casados tendem a possuir idade superior a dos solteiros, o que também diminui a propensão à migração. A existência de filhos também se mostrou fator de impedimento (Graversen et al., 2001). Dahl (2004) também observou tal relação na Dinamarca.

Korinnek e Entwisle (2005) ao analisar, na Tailândia, o envio de remessas de dinheiro para os a cidade de origem do migrante, apontam uma relação econômica importante entre as regiões de destino e de origem. Os autores descobriram maior frequência e montante de envio por parte das mulheres, em relação aos homens, e dos migrantes menos educados. 


\subsection{EVIDÊNCIAS EMPÍRICAS SOBRE O CASO BRASILEIRO}

Baeninger (2005), a partir da região de São Paulo, comprova o processo de desconcentração da migração e destaca que a ampliação das áreas de recepção de migrantes da metrópole em direção ao interior reforça o processo de dispersão populacional. A autora aponta, ainda, que os polos do interior do estado mantiveram seus papéis de catalisadores da migração intraestadual e permaneceram retendo potenciais migrantes, destacando uma maior retenção daqueles no interior em relação à metrópole.

Netto Júnior e Moreira (2003) verificaram, nas últimas décadas, uma correlação positiva entre as migrações e os níveis de renda dos estados brasileiros. Constataram, ainda, que os saldos migratórios contribuíram na determinação dos diferenciais de renda per capita dos indivíduos.

Os principais destinos dos migrantes, até 2000, constituíam os grandes aglomerados urbanos (Rigotti, 2006; Braga, 2006). No Brasil, as recentes migrações internas se mostram fundamentais ao processo de desconcentração e redistribuição populacional à medida que criam novos núcleos econômicos e desenvolvem as cidades (Matos e Braga, 2002).

Mata et al. (2007) descobriram que a cidade de São Paulo foi a cidade brasileira com maior migração qualificada no período analisado. Tais resultados confirmam a influência da trajetória histórica dos migrantes e a permanência da preferência destes pela região de São Paulo, apesar de sua desconcentração recente.

Ao analisar o período de 1986 a 2000, Rigotti (2006) constatou que a maior parte dos migrantes com alto nível educacional (15 anos ou mais de estudo) tinha, em sua origem, a região metropolitana ou a capital. Ele justificou esse fenômeno pelo fato de tais regiões possuírem um grande número de universidades e de centros de pesquisa, sendo assim fornecedores de mão de obra qualificada.

Ao analisarem o Brasil no período de 1995-2003, Ferreira e Matos (2006) constataram que, apesar de o destino dos migrantes ainda ser, principalmente, as regiões metropolitanas, estes não teriam como referência os grandes centros urbanos tradicionais. Além disso, destacam que o maior dinamismo do mercado de trabalho das regiões fora das grandes aglomerações tem atraído mão de obra migrante.

Os trabalhadores qualificados estariam distribuídos de forma polarizada ao redor ou dentro das áreas metropolitanas (Golgher, 2008). Queiroz e Golgher (2008) afirmam que cidades com maior nível de escolaridade atraem maior número de trabalhadores qualificados, em especial se forem cidades grandes.

Ao tentar verificar uma fuga de cérebros dos estados brasileiros em direção à região de São Paulo, Bezerra e Silveira Neto (2008) constataram que os únicos fluxos que se enquadram no conceito se originavam em estados com nível de desenvolvi- 
mento semelhante a São Paulo. Vale destacar que os estados, que perderam mão de obra para a unidade de federação paulista, não obtiveram perdas de produtividade.

Oliveira e Jannuzi (2005) observaram que migrações causadas por questões relativas ao custo da moradia tendem a ser maiores em pessoas residentes ou que saíram de regiões metropolitanas. Isso por tais cidades possuírem um custo de vida maior. Já as de retorno ao Nordeste ocorrem principalmente devido a dificuldades de inserção no mercado de trabalho e ao aumento da violência na região de destino.

Migrantes qualificados são atraídos por cidades com menor instabilidade social, ou seja, com menores desigualdades e menor nível de violência. Da mesma forma, são atraídos por locais com alto grau de dinamismo no mercado de trabalho, já que isso caracterizaria maiores salários. A proximidade ao litoral e invernos e verões menos rigorosos são também fatores considerados (Mata et al., 2007).

Em relação às consequências da migração destacam-se relações adversas, algumas se beneficiariam enquanto que outras seriam prejudicadas (Golgher, 2008). Quanto aos retornos da migração, Freguglia e Menezes-Filho (2007) estimaram que os trabalhadores com diploma universitário, possuiriam ganhos de $7 \%$ depois de migrar. Os migrantes de nível educacional baixo, por sua vez, tiveram uma perda de $5 \%$ de seu salário, se comparado com o não migrante.

Ferreira e Matos (2006) destacam que em um contexto de perda geral salarial, os migrantes teriam aumentos reais na sua remuneração e que a migração, como um todo, afeta positivamente os aumentos reais nos salários. Variáveis socioeconômicas mostraram que os migrantes possuem melhor ocupação, escolaridade e renda (Braga, 2006).

Oliveira e Jannuzzi (2005) observam um comportamento diferenciado entre os migrantes do sexo masculino e do feminino em termos de motivação. Enquanto os primeiros migram principalmente pela busca de melhores condições de trabalho, os segundos migram para acompanhar a família.

\section{METODOLOGIA E BASE DE DADOS}

O banco de dados construído é proveniente da RAIS-Migra do Ministério do Trabalho e Emprego (MTE) e cobre os anos de 1999 a 2002, contemplando a mobilidade de trabalhadores da indústria que pertencem ao mercado formal de trabalho. A RAIS-Migra possui a vantagem de acompanhar longitudinalmente os trabalhadores do mercado formal, a partir do código do Programa de Integração Social (PIS), permitindo a visualização dos trabalhadores no mercado de trabalho formal, a partir de sua trajetória interssetorial e geográfica e possui um alto nível de desagregação.

Contudo, a base apresenta desvantagens semelhantes às dos outros registros administrativos ao se limitar ao setor formal da economia e por conter inconsistências 
derivadas de erros de preenchimento por parte do empregador. Além disso, uma vez que as informações obtidas são um retrato do trabalhador ao final de cada ano, não é possível elaborar uma trajetória contínua de cada trabalhador no mercado.

A partir da RAIS-Migra o painel construído foi balanceado, ou seja, os mesmos trabalhadores presentes no ano de 1999 foram observados também nos outros anos. Foram retirados todos os indivíduos com indicações de informações inconsistentes entre os períodos. Tendo em vista o objetivo do trabalho, consideraram-se apenas os trabalhadores com idade entre 25 e 65 anos, que estavam no estado de São Paulo no ano base de 1999, e retirou-se da amostra todos aqueles trabalhadores que tinham o município classificado como "ignorado".

Por fim, conseguiu-se uma amostra de 9,5\% do banco total disponível. Tal amostra continha $30 \%$ de todos os trabalhadores com vínculos empregatícios em municípios do estado de São Paulo no ano de 1999. Devido à característica longitudinal da base, pôde-se identificar a localização dos mesmos trabalhadores no ano de 2000, 2001 e 2002.

A composição do banco foi de 1.728 .400 trabalhadores a cada ano, constituindo-se 6.913.577 observações. Desses trabalhadores, 9,45\% (163.412) constituem trabalhadores que mudaram de município no período 1999-2000. Cerca de 8,84\% (152.754) do total migraram em 2001 e 8,45\% (146.040) em 2002. Do total de trabalhadores da amostra, aproximadamente, $4 \%$ mudam de setor de atuação ao migrar de cidade.

Neste trabalho, é considerado migrante o trabalhador que tenha mudado de município no qual possuía vínculo empregatício nos anos de 1999 a 2002. Como o objetivo é observar os transbordamentos de conhecimento, que ocorrem a partir do estado de São Paulo para as outras regiões, consideraram-se, nas análises, apenas aqueles indivíduos que saíram do estado no período. Da mesma forma, denominam-se setores intensivos em tecnologia, aqueles considerados de alta e média-alta intensidade tecnológica de acordo com a relação entre gastos com P\&D e valor agregado na estrutura industrial brasileira.

\subsection{VARIÁVEIS UTILIZADAS}

A idade do trabalhador, seu gênero, seu município, sua renda, seu grau de escolaridade, o tamanho da firma com a qual possui vínculo e o seu setor de atividade foram originárias da RAIS-Migra. A variável "tamanho da população das cidades" foi retirada da base de dados do IBGE (Censo 2000).

Como se busca avaliar os indivíduos no mercado de trabalho, a idade dos trabalhadores foi agrupada em três faixas: de 25 a 35 anos, 36 a 55 anos e acima de 56 anos. Para identificar o porte das cidades foi definida como cidade pequena aquele 
município com menos de 100 mil habitantes, cidade média como aquele com população menor que 500 mil e maior que 100 mil habitantes, cidade grande como aquela com mais de 500 mil e menos de 1 milhão de habitantes, e metrópole, acima de 1 milhão de habitantes. No trabalho considerou-se pequena empresa aquela com até 99 empregados, média empresa a de 100 a 499 empregados, e grande empresa aquela com mais de 500 empregados.

Como se deseja avaliar os trabalhadores que saem de São Paulo, o ano base definido foi 1999. Nesse ano, portanto, todos os trabalhadores se encontram em municípios do estado de São Paulo, constituindo a origem. A partir de 1999, segue-se a trajetória dos trabalhadores em direção ao município de destino, que pode ser para municípios de São Paulo ou para qualquer outra unidade federativa. Visando medir o nível de qualificação do indivíduo, sua educação foi subdivida em nove categorias, variando de analfabeto a superior completo. Serão considerados trabalhadores qualificados apenas aqueles que possuírem nível superior completo.

Para caracterizar os setores, utilizaram-se as divisões das atividades econômicas segundo a classificação CNAE-95. As divisões industriais são as categorias que correspondem às divisões CNAE-15 a 36. As outras divisões correspondem, principalmente, a setores relacionados com serviços. As divisões industriais foram classificadas segundo as subdivisões sugeridas por Furtado e Carvalho (2005), detalhadas na próxima seção.

\subsection{CLASSIFICAÇÃO DOS SETORES INDUSTRIAIS SEGUNDO A INTENSIDADE TECNOLÓGICA}

Furtado e Carvalho (2005) desenvolveram uma taxonomia de intensidade tecnológica setorial para a indústria brasileira, assumindo particularidades do esforço tecnológico brasileiro vis-à-vis o esforço de países desenvolvidos. Assim, destacam que a agrupação dos setores por intensidade tecnológica feita pela Organização para Cooperação e Desenvolvimento Econômico (OCDE) não é apropriada para a realidade nacional. Com base nos indicadores de Pesquisa\&Desenvolvimento (P\&D) em relação ao valor agregado industrial os autores encontram quatro categorias de setores por intensidade tecnológica: alta intensidade, média-alta, média-baixa e baixa intensidade.

A taxonomia proposta é mostrada no Quadro 1 adiante. 
Quadro 1 - Classificação dos setores da indústria brasileira por intensidade tecnológica

\begin{tabular}{l|l}
\hline \multirow{2}{*}{ Baixa } & $\begin{array}{l}\text { Alimentos, bebidas e fumo; têxtil, confecção e calçados; madeira, papel, celulose, } \\
\text { edição e gráfica; minerais não metálicos, metalúrgica básica, produtos metálicos, } \\
\text { móveis e diversos (CNAE-15 a 22, e a divisão 26). }\end{array}$ \\
\hline Média-baixa & $\begin{array}{l}\text { Refino e outros, química, borracha e plástico, farmacêutica (CNAE-23, 24, 25, 27, } \\
28 \text { e 33). }\end{array}$ \\
\hline Média-alta & $\begin{array}{l}\text { Informática, máquinas e equipamentos, instrumentos e veículos automotores } \\
\text { (CNAE-29, 30, 34 e 36). }\end{array}$ \\
\hline Alta & $\begin{array}{l}\text { Material e máquinas elétricas, eletrônica e outro material de transporte } \\
\text { (CNAE-31, 32 e 35). }\end{array}$ \\
\hline
\end{tabular}

Fonte: Furtado e Carvalho (2005).

\subsection{MATRIZES DE TRANSIÇÃO}

Por meio da matriz de transição, apresentada no apêndice 1, é possível perceber de que divisão o trabalhador emigrou e para onde ele imigrou. Assim, verifica-se toda a trajetória que contribui para concentrar trabalhadores em determinados municípios e/ ou setores. Dessa forma, os resultados apresentados nas linhas representam as saídas dos trabalhadores e os resultados apresentados nas colunas representam as imigrações.

A fim de se verificar a localização dos migrantes qualificados, nos períodos t (após a migração) e t-1 (antes de migrar) foi construída uma matriz de transição por municípios agrupando-se os resultados por porte de cidade. Mostraram-se apenas as desagregações das cidades de grande porte e das metrópoles de dentro do estado de São Paulo.

Em relação aos setores construiu-se matriz de transição dos trabalhadores migrantes qualificados que saem do estado de São Paulo no período $t$ - 1 e mudam de setor (Apêndice 1). Nela, mostra-se a transição dos trabalhadores migrantes entre os setores das divisões 15 a 36 e da agregação dos setores fora desse intervalo. Assim, não há fluxos na diagonal principal, exceto na coluna "outros" por essa constituir uma agregação de todas as outras divisões fora a CNAE-15 a CNAE-36, formada principalmente por setores relacionados com serviços. Observa-se nessa transição uma preferência dos trabalhadores por setores, no destino, semelhantes em termos de nível tecnológico, ao da origem. Contudo, ocorre uma grande imigração de trabalhadores para setores dentro da categoria “outros". Entretanto, o movimento contrário não se mostra tão intenso.

\section{4 ÍNDICES}

Com base em Bezerra e Silveira Neto (2008), foram utilizados dois índices, a taxa de migração e a taxa de perdas agregadas gerada pela migração, por município, para avaliar a perda de pessoas qualificadas causada pela emigração. As duas taxas foram 
modificadas da versão apresentada pelos autores a fim de se captar todos os trabalhadores.

O primeiro índice utilizado, a taxa de migração ( $\varphi$ t descrito na fórmula 1) capta a perda bruta de trabalhadores devido à emigração. Através dele pode-se inferir quanto, em porcentagem, o município perde de mão de obra através da migração por medir a relação entre os migrantes e a população da origem. Valores altos indicam uma grande perda de trabalhadores.

$$
\varphi_{t}=100 \frac{M_{t}}{E_{t}}
$$

$\mathrm{Na}$ equação, $\mathrm{M}_{\mathrm{t}}$ corresponde ao número de migrantes e $\mathrm{E}_{\mathrm{t}}$ ao número de trabalhadores na origem. Este índice mede a emigração à medida que toma os emigrantes como porcentagem dos trabalhadores.

Já o segundo índice se baseia na proposição de que a perda de trabalhadores qualificados seria prejudicial para a economia. Através dele se mede as perdas agregadas geradas pela emigração $\left(\gamma_{t}\right)$ na forma descrita abaixo:

$$
\gamma_{t}=\frac{G_{t}^{M}}{G_{t}^{E}}
$$

Em que $G_{t}^{M}$ corresponde à parcela de trabalhadores qualificados entre os migrantes e $G_{t}^{E}$ a parcela de qualificados na origem. Esse índice varia no intervalo $[0,+\infty)$, sendo seu valor crítico igual a 1 (um), que corresponde a quando a economia começa a sofrer perdas de população qualificada. Quando $\gamma$ é maior que 1 (um), a proporção de qualificados entre os migrantes supera a de trabalhadores qualificados da região de origem.

\section{ANÁLISE EMPÍRICA DO CASO DE SÃO PAULO}

\subsection{CARACTERÍSTICAS PESSOAIS DOS TRABALHADORES DO ESTADO DE SÃO PAULO}

A tabela 1 apresenta o perfil dos migrantes, não migrantes, migrantes pertencentes a setores intensivos em tecnologia e migrantes que mudam de setor. Pode-se observar que $6,43 \%$ dos trabalhadores são migrantes. Deve-se salientar, no entanto, que só estão sendo considerados os migrantes que saem do estado de São Paulo no período analisado. 


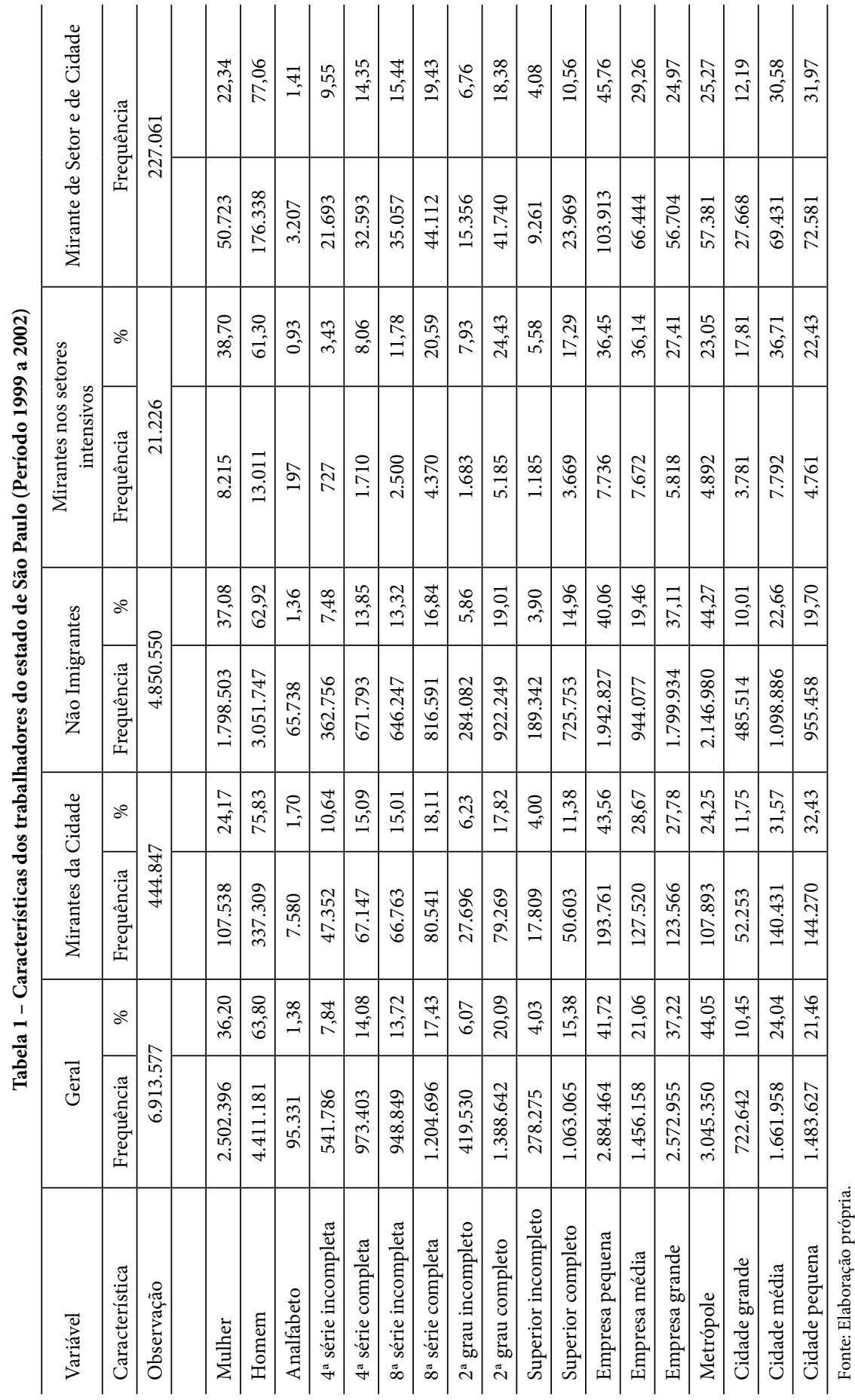


Aproximadamente 75,83\% dos migrantes, 61,30\% dos migrantes em setores de alta intensidade e $77,66 \%$ dos migrantes de cidade e setor pertencem ao sexo masculino. Tal ocorrência se mostra de acordo com a teoria de migração que afirma que homens têm maior probabilidade de migrar do que mulheres (Ehrenberg e Smith, 1992). Porém, deve-se considerar o fato de que existirem mais migrantes homens do que mulheres possa estar refletindo o maior número de homens no banco de dados, cerca de $63,80 \%$.

Outra tendência apontada na literatura confirmada pelo banco foi o fato de os migrantes terem idade média inferior à idade média dos trabalhadores em geral, enquanto a primeira era de 38 anos a segunda era de 39 anos. Kulu e Billari (2004) afirmam que pessoas mais novas têm maior probabilidade de migração do que as mais velhas.

Ao analisar o nível educacional, exclusive o grupo de migrantes de setor e de cidade, observa-se que a maior parcela de trabalhadores pertencentes aos grupos possui qualificação equivalente ao $2^{\circ}$ grau completo. No grupo dos migrantes $(11,38 \%)$ e, em especial, nos migrantes em setores intensivos em tecnologia (17,29\%) observa-se um grande número de trabalhadores com nível superior completo, o que está de acordo com a literatura. Vale ressaltar que os migrantes de setores intensivos em tecnologia possuem $22,87 \%$ de sua composição de trabalhadores com nível superior completo ou incompleto, maior proporção entre os grupos.

Em todos os grupos analisados, a maioria dos trabalhadores se encontra em empresas de pequeno porte, sendo que no caso dos migrantes, o percentual se refere à empresa de destino do trabalhador. Nos migrantes de setores intensivos em tecnologia o percentual de trabalhadores das empresas de pequeno e médio porte é quase igual, assim, aproximadamente, $72 \%$ destes estão vinculados a uma empresa de pequeno ou médio porte em sua cidade de destino. No caso dos migrantes de cidade e de setor, esse percentual é ainda maior, aproximadamente 75\%. Deve-se levar em conta que, no Brasil, a maioria dos trabalhadores brasileiros está vinculada a empresas de pequeno porte.

Ao analisar o destino dos trabalhadores, observa-se uma tendência de concentração dos migrantes nas cidades de pequeno e médio porte (64\%). Dos migrantes de setores intensivos em tecnologia, 59\%, em seu destino, se localizam em cidades desses portes, e entre os migrantes de setor e cidade, esse percentual sobe para $62 \%$. Entre os não migrantes, assim como na amostra como um todo, há um maior número de trabalhadores nas metrópoles, cerca de $44 \%$. 


\subsection{MIGRAÇÕES URBANAS POR SETOR}

A tabela 2 descreve o destino e a origem dos trabalhadores qualificados que saíram do estado de São Paulo entre 1999 a 2002, por intensidade tecnológica do setor a que pertencem.

Tabela 2 - Setores de origem e destino de trabalhadores migrantes qualificados por intensidade tecnológica (Período entre 1999-2002)

\begin{tabular}{|c|c|c|c|c|c|c|c|}
\hline & \multicolumn{6}{|c|}{ Destino } \\
\hline & & Alta & Média-Alta & Média-Baixa & Baixa & Outros & Total \\
\hline \multirow{6}{*}{ 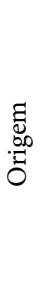 } & Alta (\%) & 34,34 & 14,19 & 6,65 & 2,81 & 42,02 & 1.459 \\
\hline & Média-alta (\%) & 6,60 & 47,45 & 8,87 & 3,22 & 33,85 & 2.514 \\
\hline & Média-baixa (\%) & 2,12 & 6,50 & 51,72 & 4,24 & 35,42 & 3.492 \\
\hline & Baixa (\%) & 1,69 & 4,86 & 7,45 & 44,55 & 41,45 & 2.965 \\
\hline & Outros (\%) & 1,29 & 1,80 & 2,91 & 2,51 & 91,48 & 40.173 \\
\hline & Total & 1.311 & 2.496 & 3.616 & 2.601 & 40.679 & 50.603 \\
\hline
\end{tabular}

Percentual em relação ao total da origem.

Fonte: Elaboração própria.

Em relação às transições dentro das divisões 15 a 36, é importante salientar que grande parte dos trabalhadores se desloca para setores com intensidade tecnológica compatível ao de sua origem. Em todas as divisões há uma porcentagem maior de trabalhadores em setores com intensidade igual na origem e no destino.

À medida que o nível de intensidade vai se difereciando do nível a que o trabalhador pertencia, a porcentagem diminui. É facil notar essa tendência ao se observar os trabalhadores que em seu destino estão fora das divisões 15 a 36, a categoria "outros", o que revela saída de trabalhadores de setores industriais de baixa tecnologia para setores não industriais. Apenas 8,51\% dos migrantes qualificados que, em sua origem estão em setores dessa categoria, dirigem-se para um dos setores das divisões 15 a 36 .

Contudo, essa divisão constitui importante destino dos migrantes qualificados. Tal fato pode ter ocorrido em função de um possível "enxugamento" do quadro de trabalhadores da indústria no período 1999-2002, o que, por sua vez, é coerente com a tendência de aumento da terceirização de funções industriais. Vale ressaltar que o setor de serviços, tradicionalmente, constitui um refúgio para os trabalhadores industriais desempregados.

Dos trabalhadores que em sua origem estão em setores de alta intensidade tecnológica, 34,34\% vão para setores também de alta intensidade e 14,19\% para os setores de média-alta. Apenas 9,46\% se dirigem a setores não intensivos em tecnologia (baixa ou média baixa intensidade tecnológica). Nota-se ainda que mais trabalhadores que 
estavam em setores de média-alta se dirigem para setores de média-baixa $(8,87 \%)$ do que o contrário $(6,50 \%)$.

Além disso, a proporção de trabalhadores de setores de média-baixa intensidade que se dirige para o de média-alta é menor do que os de alta que se dirigem aos de média-alta. Tal fato pode se dar devido à facilidade de um indivíduo com conhecimento tecnológico específico de setor de média-alta intensidade se dirigir para uma indústria com menor intensidade do que o contrário, tendo em vista que dentro de setores intensivos em tecnologia há aqueles cujo conhecimento permeia toda a cadeia produtiva industrial, como eletroeletrônica.

A partir do total de trabalhadores migrantes qualificados mostrado na tabela 2, vale ressaltar que a maioria destes se aglomera em setores não intensivos em tecnologia e na categoria de serviços (outros), o que reflete o menor tamanho relativo de setores de alta tecnologia $v i s-\grave{a}$-vis, setores tecnologicamente maduros. Em relação aos trabalhadores qualificados que saem do estado de São Paulo e mudam de setor de atuação (Apêndice 01), os setores industriais que mais recebem trabalhadores de outros setores são as divisões de fabricação de máquinas e equipamentos (CNAE29), de fabricação de veículos automotores (CNAE-34) e de fabricação de produtos químicos (CNAE-24), respectivamente. Dentre as divisões 15 a 36, aquela que na origem concentra o maior número de trabalhadores qualificados é a divisão industrial CNAE-24, seguida da de fabricação de produtos alimentícios e bebidas (CNAE-15).

Nota-se que os migrantes qualificados tendem a se concentrar em setores com maior intensidade tecnológica, em especial ao mudarem de setor, uma vez que os setores não intensivos em tecnologia e não pertencentes às divisões 15 a 36 são pouco procurados.

As divisões industriais de fabricação de produtos do fumo (CNAE-16) e de fabricação de coque, refino de petróleo, elaboração de combustíveis (CNAE-23) são as que, dentre as CNAE-15 a CNAE-36, menos recebem e enviam trabalhadores. Tal fato pode ser justificado por tais divisões necessitarem de um conhecimento específico não plenamente apropriado a outros setores tecnológicos. Os setores pertencentes à subdivisão "outros" têm maior transição de trabalhadores vinda de setores de baixa e média-baixa intensidade, o que pode refletir maior tendência de redução de pessoal empregado ou terceirização.

Os migrantes qualificados, pertencentes aos setores de alta intensidade tecnológica, aglomeram-se, principalmente, na divisão de fabricação de máquinas, aparelhos e materiais elétricos (CNAE-31), sendo que a maior transição de trabalhadores vindos desse setor ocorre para o de máquinas e equipamentos (CNAE-29). Os trabalhadores educados nos setores de média-alta intensidade se aglomeram principalmente na divisão industrial CNAE-29, sendo que se dirigem principalmente para o setor de 
fabricação de veículos automotores (CNAE-34) e para o de fabricação de máquinas, aparelhos e materiais elétricos (CNAE-31).

Analisando-se os setores de alta intensidade tecnológica, percebe-se que, se comparados com os outros, estes são os que menos enviam migrantes. Isso se justifica pelo conhecimento intrínseco (tácito) que tais trabalhadores possuem por trabalhar em setores que envolvem alto nível de conhecimento tecnológico.

\subsection{MIGRAÇõES URBANAS POR PORTE DE CIDADE}

A cidade de São Paulo possui saldo de migração (imigração menos emigração) negativo tanto ao se analisar migrantes quanto migrantes qualificados. Em relação ao fluxo de migrações, a capital paulista é a cidade com maior índice do estado de São Paulo para o período de 1999-2002. Observa-se, contudo, que a cidade de São Paulo por possuir o menor saldo do estado (maior saldo negativo), passa por um processo de desconcentração que se estende desde o início do processo de reversão da polarização no Brasil (Diniz, 1993). Porém, ao se comparar migrantes e migrantes qualificados, percebe-se que, entre as cidades grandes do estado de São Paulo, a maioria apresenta saldo negativo quando se analisa os primeiros enquanto que em relação aos segundos a maioria apresenta saldo positivo.

Isso é compatível com a ideia de que as metrópoles ainda exercem forte atração sobre o trabalhador qualificado por concentrar as funções administrativas e outras mais complexas do processo produtivo. Ao mesmo tempo, as funções meramente operacionais são deslocadas para cidades menores, atraindo trabalhadores menos qualificados. Os índices construídos mostrados nas figuras 1 e 2 se mostram importantes à medida que captam uma perda bruta de capital humano por parte das cidades de origem. A migração se torna fator-chave para o desenvolvimento regional, uma vez que proporciona mão de obra e capital humano à região de destino. Porém, de forma análoga pode prejudicar a produtividade da cidade de origem.

A taxa de migração determina o percentual dos trabalhadores que saem de sua cidade, medindo assim, a perda bruta de trabalhadores devido à emigração. Tal medida torna possível captar uma possível perda produtiva devido à perda de mão de obra local. Já a taxa de perda agregada de capital humano mede a perda de pessoal qualificado. Através dele, pode-se determinar se há, proporcionalmente, mais trabalhadores qualificados entre os emigrantes ou entre os trabalhadores da região. Assim sendo, ao considerarmos uma perda de trabalhadores qualificados como sendo prejudicial à localidade que envia esses migrantes, pode-se determinar se o fenômeno somente proporciona uma difusão de conhecimento ou se também provoca uma perda de produtividade da cidade de origem. 
Figura 1 - Taxa de migrantes no período entre 1999-2002 para os municípios do estado de São Paulo

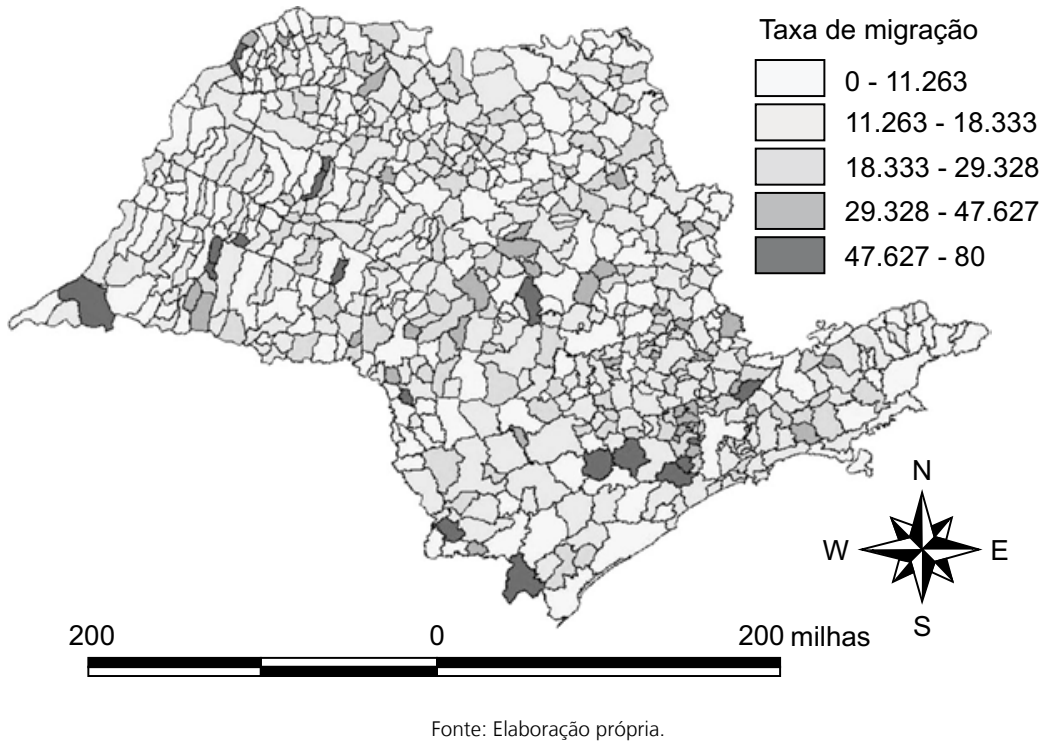

Através das figuras 1 e 2, é possível perceber o nível de atividade migratória do estado de São Paulo. A capital paulista possui uma perda de mão de obra de $10 \% \mathrm{em}$ relação ao total de trabalhadores. Em termos de perda agregada de capital humano, nota-se que a cidade possui uma perda muito baixa, cerca de 0,09.

A cidade de Guarulhos, por sua vez, possui taxa de migração de 18\%, sendo superior à da capital. Além disso, seu índice de perdas agregadas devido à migração de trabalhadores qualificados foi de 0,25 , também superior à paulistana, mas não suficientemente alta para causar um efeito negativo no desenvolvimento regional.

As cidades com maior taxa de migração são Barra do Chapéu, Brejo Alegre e Sagres, respectivamente com 80\%, 78,15\% e 75,36\%. Apesar do alto nível de emigração, ao se analisar a perda de pessoal qualificado, notam-se níveis baixos $(0,000,0,538 \mathrm{e}$ 0,583 , respectivamente), indicando que o processo de perda de mão de obra se concentra entre os pouco qualificados. Entre as cidades paulistas com população entre 500 mil e 1 milhão de habitantes em 2000, São José dos Campos possuía 11,26\% de seus trabalhadores saindo da cidade e 0,121 de perda de trabalhadores qualificados. A cidade de Campinas apresentava taxa de migração de $15,42 \%$ e perda agregada de 0,146. São Bernardo do Campo possuía a maior taxa de migração e de perda de trabalhadores qualificados entre as três, $16,75 \%$ e 0,204 , respectivamente. 
Figura 2 - Taxa de perda agregada no período entre 1999-2002 para os municípios do estado de São Paulo

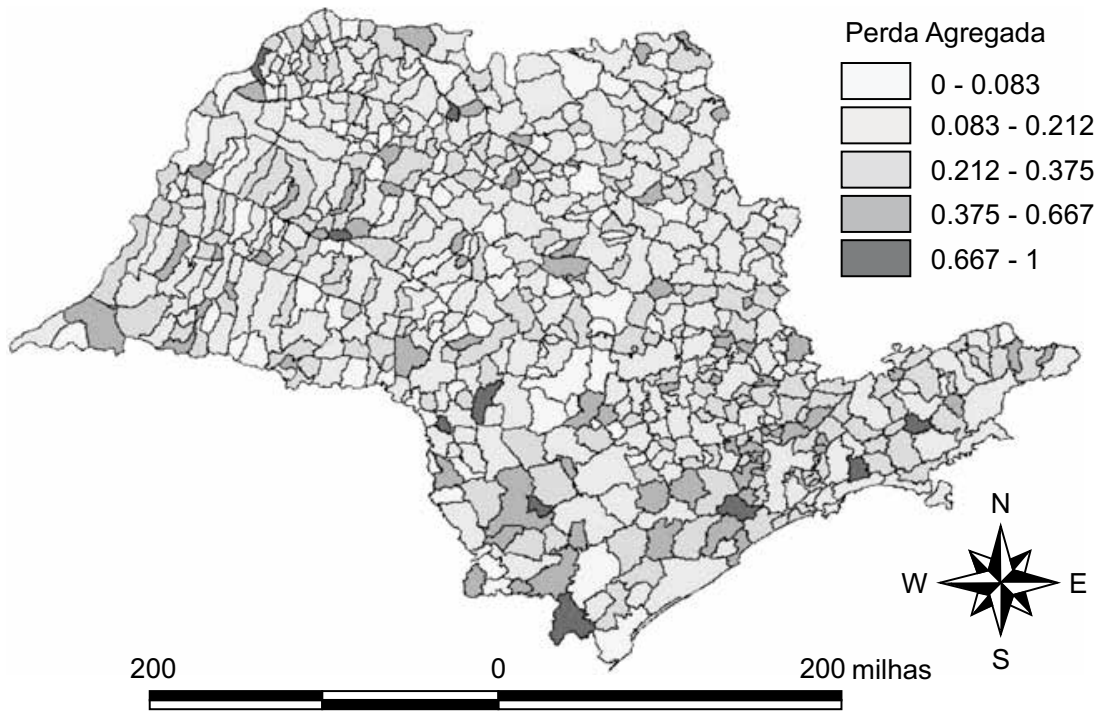

Fonte: Elaboração própria.

Em relação às perdas agregadas sofridas pelos municípios devido à emigração, as cidades com perda agregada igual a 1 (um), ou seja, sobre o ponto crítico, são cidades pequenas como Barra do Turvo, Redenção da Serra e Taquarivai. Das cidades que obtiveram índice igual a zero, sua maioria eram cidades de pequeno porte. Duas cidades da região metropolitana de São Paulo apresentam índices de perda agregada próximos de 1 , Juquitiba $(0,78)$ e Biritiba-Mirim $(0,71)$. Tal fato pode ser justificado pela atração que cidades maiores da região podem exercer nos trabalhadores dessas cidades uma vez que a primeira possui taxa de migração superior a 50\%.

Contudo, o estado como um todo apresenta baixas taxas de migração e de perda agregada de capital humano. $\mathrm{O}$ que pode se justificar por tal região estar sofrendo uma desconcentração das atividades produtivas e uma reversão do processo de atração em relação ao resto do país.

A tabela 3 apresenta a distribuição dos migrantes qualificados em relação ao porte das cidades de destino e origem. Embora 34,91\% dos destinos preferidos ainda sejam cidades metropolitanas, destaca-se que $49,77 \%$ dos migrantes qualificados preferem cidades médias $(30,42 \%)$ e pequenas $(19,35 \%)$. Além disso, constata-se que a maior parte dos migrantes qualificados estava, na sua origem, em uma metrópole $(41,74 \%)$.

O destino escolhido por migrantes, com nível superior completo, que estavam em uma metrópole, respectivamente, foi de $38,82 \%$ para cidades médias e $21,10 \%$ 
para cidades grandes. Desses migrantes, sua maioria $(57,76 \%)$ se dirigiu para cidades pequenas ou médias. Isso pode ser explicado pela busca de uma melhor qualidade de vida por parte dos trabalhadores devido aos custos de congestão dos grandes centros. Tal fenômeno se torna importante à medida que promove transbordamentos de conhecimento de cidades grandes para menores.

Tabela 3 - Origem e destino dos trabalhadores qualificados que saíram do estado de São Paulo em relação ao porte urbano (Período entre 1999-2002)

\begin{tabular}{|c|c|c|c|c|c|c|c|}
\hline & & \multicolumn{6}{|c|}{ Destino } \\
\hline \multirow{7}{*}{ בี } & Cidade & Metrópole & Grande & Média & Pequena & Total & \\
\hline & Metrópole & 20,60 & 21,10 & 38,82 & 19,48 & 20.986 & $(41,47 \%)$ \\
\hline & Grande & 51,21 & 8,94 & 26,24 & 13,62 & 7.050 & $(13,93 \%)$ \\
\hline & Média & 46,84 & 13,05 & 23,32 & 16,79 & 13.835 & $(27,34 \%)$ \\
\hline & Pequena & 37,25 & 10,17 & 24,86 & 27,71 & 8.732 & $(17,26 \%)$ \\
\hline & Total & 17.666 & 7.751 & 15.394 & 9.792 & & 50.603 \\
\hline & & $(34,91 \%)$ & $(15,32 \%)$ & $(30,42 \%)$ & $(19,35 \%)$ & & $(100,00 \%)$ \\
\hline
\end{tabular}

Nota: Percentual em relação ao total na origem.

Fonte: Elaboração própria.

Dentre os migrantes qualificados que estavam em cidades grandes, médias e pequenas, respectivamente, $51,21 \%, 46,84 \%$ e $37,25 \%$ deles, ao migrar, se dirigiram a uma metrópole. $\mathrm{O}$ segundo destino mais procurado por aqueles de cidades grandes $(26,24 \%)$ e médias $(23,32 \%)$ são as cidades médias. Os trabalhadores de cidades pequenas $(24,86)$ procuram depois das metrópoles, cidades médias.

Ao analisar a tabela 4, percebe-se que os migrantes com escolaridade superior completo tendem a permanecer no estado de São Paulo após a migração. Tal evidência corrobora a literatura que afirma que os migrantes tendem a se dirigir para cidades próximas à sua origem (Lucas, 2001).

As cidades de origem onde os migrantes qualificados se aglomeram são São Paulo, Guarulhos e Campinas. Já as de destino são a capital paulista, São José dos Campos e São Bernardo do Campo. A cidade de São Paulo se destaca como a principal receptora e emissora de migrantes qualificados, o que confirma, ainda, seu importante papel na região, apesar da desconcentração que vem sofrendo nos últimos anos.

Dentre as cidades grandes paulistas, Campinas, São Bernardo do Campo e São José dos Campos se destacam como principal destino dos migrantes originários de cidades grandes do estado. São José dos Campos, seguida da cidade de São Paulo, constitui o principal destino dos migrantes vindos de metrópoles. 


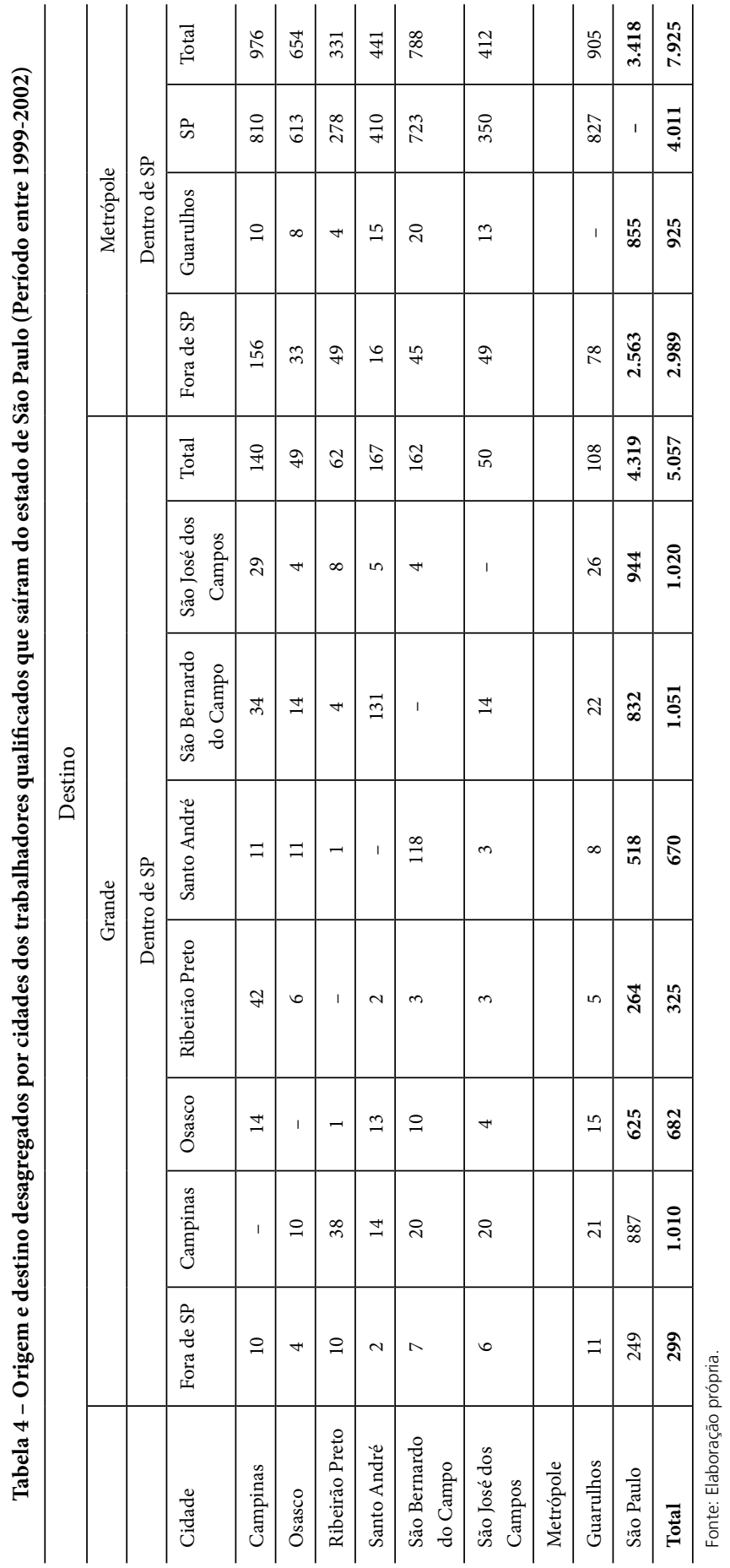


O destino menos desejado, dentro do estado de São Paulo, dos migrantes paulistas residentes em cidades grandes é Osasco. A cidade de Guarulhos também constitui um destino menos desejado do que outras cidades de mesmo porte fora do estado.

Dos trabalhadores que se dirigem às cidades de grande porte, aqueles vindos de São Paulo e Guarulhos têm como principal destino a cidade de São José dos Campos. O destino mais procurado pelos migrantes altamente qualificados de Santo André, depois de São Paulo, é São Bernardo do Campo, cujos trabalhadores se destinam em massa a Santo André.

O fenômeno que ocorre entre Santo André e São Bernardo do Campo pode ser explicado de duas formas. A primeira é a proximidade das regiões. A segunda é o fenômeno conhecido como migração de retorno, ou seja, o fato de muitas pessoas de São Bernardo do Campo se dirigirem para Santo André, por exemplo, pode fazer com que muitas pessoas voltem de São Bernardo do Campo para Santo André, ou o contrário.

\subsection{CONSIDERAÇÕES FINAIS}

Apresentou-se neste artigo a análise exploratória do comportamento dos migrantes qualificados da indústria que se movem a partir de algum município do estado de São Paulo, entre os anos de 1999 a 2002. Em linhas gerais, os resultados obtidos mostram que o perfil médio dos migrantes de setores intensivos em tecnologia é do sexo masculino e já ingressaram ou concluíram, em sua maioria, o nível superior de ensino.

Ao migrar e mudar de setor, os trabalhadores qualificados se dirigem a setores com intensidade tecnológica compatível ao de sua origem. Isso se justifica pelo conhecimento tácito e específico que tais trabalhadores adquirem nos setores de origem. Contudo, a categoria "outros", composta especialmente pelo setor de serviços, constitui importante destino dos migrantes qualificados. Tal fato pode ter ocorrido em função de um possível "enxugamento" do quadro de trabalhadores da indústria no período 1999-2002. Além disso, observa-se uma maior proporção de trabalhadores de setores tecnologicamente intensivos se dirigindo para setores não intensivos, do que o movimento contrário. Justifica-se tal fenômeno por uma incompatibilidade de conhecimento tecnológico.

Em relação ao fluxo de migrações, a capital paulista é a cidade com maior índice do estado de São Paulo para o período analisado. Observa-se, contudo, que a cidade de São Paulo possui o menor saldo do estado (maior saldo negativo), o que demonstra que esta passa por um processo de desconcentração. As cidades grandes possuem saldo positivo de migrantes qualificados. 
A capital paulista possui uma perda de mão de obra de $10 \%$ em relação ao total de trabalhadores, porém, em termos de perda agregada de capital humano, nota-se que a cidade possui uma perda muito baixa, cerca de 0,09 . As cidades com maior taxa de migração sofrem um processo de perda de mão de obra dos menos qualificados uma vez que o índice de perda agregada é baixo. Porém, o estado como um todo apresenta baixas taxas de migração e de perda agregada de capital humano.

Outra característica relevante dos migrantes se refere à sua concentração nas grandes cidades. A maioria dos migrantes qualificados estava, em sua origem, em uma metrópole. Depois das metrópoles, os trabalhadores qualificados procuram cidades de porte médio. A maior parte dos trabalhadores se dirige para metrópoles, com exceção dos originários de cidades de mesmo porte, cujo principal destino são as cidades médias.

A maior parte dos migrantes com nível superior completo que estavam em uma metrópole se dirigiu para cidades pequenas ou médias. Isso pode ser explicado pela busca de uma melhor qualidade de vida devido aos custos de congestão dos grandes centros. Os migrantes com nível superior completo tendem a permanecer no estado de São Paulo após a migração. A capital paulista se destaca como a principal receptora e emissora de migrantes qualificados, o que confirma ainda seu papel importante na região.

Dado o caráter exploratório do presente estudo e a importância acerca do tema, uma extensão futura deste trabalho pode envolver a implementação de um modelo econométrico de regressão logística controlado para efeitos não observáveis. Isso permitiria uma análise mais detalhada sobre os determinantes da mobilidade de trabalhadores qualificados, corrigindo o viés de auto-seleção associado à decisão de mudar de município. Além disso, diante da importância desse tipo de mobilidade para o crescimento regional, outra possível extensão seria a construção de um modelo econométrico espacial para a avaliação de quais características municipais atraem o migrante qualificado.

\section{REFERÊNCIAS}

BEINE, M. et al. "Brain drain and human capital formation in developing countries: winners and losers". The Economic Journal, v. 118, p. 631-652, abr. 2008.

BEZERRA, F.M.; SILVEIRA NETO, R.M. "Existe 'Fuga de Cérebros' no Brasil? evidências a partir dos censos demográficos de 1991 e 2000”. Revista Economia, Brasília, v. 9, n. 3, p. 435-456, dez. 2008.

BORJAS, G.J. “Labor mobility”. In: BORJAS, G.J. Labor economics. Singapura: McGraw-Hill Book Co, 1996. p. 279-317. 
BORJAS, G.J. “The labor market impact of high-skill immigration”. American Economic Review, v. 95, n. 2, p. 56-60, 2005.

BOVER, O.; ARELLANO, M. "Learning about migration decisions from de migrants: using complementary dataset to model intra-regional migrations in Spain". Population Economics, v. 15, p. 357-380, 2002.

BRAGA, F.G. "Migração interna e urbanização no Brasil contemporâneo: um estudo da rede de localidades centrais do Brasil (1980/2000)". In: Encontro Nacional de estudos populacionais, 15. Anais: Caxambu, 2006.

CHISWICK, B.R. "The effect of americanization on the earnings of foreign-born men". Journal of Political Economy, v. 86, p. 897- 921, 1978.

CHISWICK, B. R. "Are immigrants favorably self-selected? An economic analysis". In: BRETTELL, C. D.; HOLLIFIELD, J.F. Migration theory: talking across the disciplines. Nova York: Routledge, 1999. p. 52-75.

DAHL, M.S. Embodied knowledge diffusion, labor mobility and regional dynamics: do social factors limit the development potential of regions? In: DRUID SUMMER CONFERENCE, 2004, Elsinore. Industrial Dynamics, Innovation and Development. Dinamarca: VBN, 2004.

DEBELLE, G.; VICKERY, J. "Labour market adjustment: evidence on interstate labour mobility”. (Texto para discussão: 9801). Reserve Bank of Australia, 1998

DINIZ, C.C. "Desenvolvimento poligonal no Brasil: nem desconcentração, nem contínua polarização”. Nova Economia, v. 3, n. 1, 1993.

DINIZ, C.C.; GONÇALVES, E. Knowledge economy and regional development in Brazil. In: LES TROISIÈMES JOURNÉES DE LA PROXIMITÉ -CONGRESS ON PROXIMITY, 3, Paris, 2001.

EHRENBERG, R.G.; SMITH, R.S. A moderna economia do trabalho. 5 ed. São Paulo: Makron Books, 1992.

FELDMAN, M.P. “The new economics of innovation, spillovers and agglomeration: a review of empirical studies". Economics of Innovation and New Technology, v. 8, p. 5-25, 1999.

FERREIRA, R.N.; MATOS, R. Migração de trabalhadores no mercado formal brasileiro entre 1995 e 2003 e as tendências da reestruturação territorial. In: ENCONTRO NACIONAL DE ESTUDOS POPULACIONAIS, 14, 2004, Caxambu. Anais. Belo Horizonte: ABEP, 2006.

FREGUGLIA, R.S., MENEZES-FILHO, N.A. Inter-regional and inter-industry wage differentials with individual heterogeneity: estimates using Brazilian data. Midwest Economics Association Conference, 2007. Seção 5I: Labor Economics.

FURTADO, A.T., CARVALHO, R.Q. "Padrões de intensidade tecnológica da indústria brasileira: um estudo comparativo com os países centrais”. São Paulo em Perspectiva, São Paulo, v. 19, n. 1, p. 70-84, 2005. 
GOLGHER, A.B. "As cidades e a classe criativa no Brasil: diferenças espaciais na distribuição de indivíduos qualificados nos municípios brasileiros". Revista Brasileira de Estudos da População, v. 25, p. 109-129, 2008.

GRAVERSEN, E.K.; FRIIS-JENSEN, K. Job mobility implications of the human resources in science and technology definition: illustrated by empirical numbers from register data. In: OECD (Org). Innovative people: mobility of skilled personnel in national innovation systems. 2001. p. 45-58.

GRAVERSEN, E.K et al. Migration between the nordic countries: what do register data tell us about the knowledge flow? In: OECD (Org). Innovative people: mobility of skilled personnel in national innovation systems. 2001. p. 261-286.

JACKMAN, R.; SAVOURI, S. "Regional migration in Britain: an analysis of gross flows using NHS central register data”. The Economic Journal, v. 102, n. 415, p. 1433-1450, Nov., 1992.

JAUHIAINEN, S. "Regional concentration of highly educated couples". In: POOT, J.; WALDORF, B.; VANWISSEN, L. (eds.). Migration and human capital. Northampton: Cheltenham, 2008. c. 5.

KORINNEK, K.; ENTWISLE, B. Obligation and opportunity: the influence of gender, earnings, and household obligations upon Thai migrants' remittance behavior. In: ANNUAL MEETING OF THE POPULATION ASSOCIATION OF AMERICA, Califórnia. Anais. 2005.

KULU, H.; BILLARI, F.C. "Multilevel analysis of internal migration in a transitional country: the case of Estonia”. Regional Studies, v. 38, n. 6, p. 697-696, 2004.

LAAFIA, I.; STIMPSON, A. Using the community labour force survey to develop mobility rates on human resources in science and technology. In: OECD (Org). Innovative people: mobility of skilled personnel in national innovation systems. 2001. p. 129-141.

LUCAS, R.E.B. The effects of proximity on developing country population migrations. Journal of economic geography, Boston, n. 1, p. 323-339, 2001.

MATA, D. da; et al.Quais características das cidades determinam a atração de migrantes qualificados?. In: ENCONTRO REGIONAL DE ECONOMIA, 12, 2007, Fortaleza. Anais. 2007

MATOS, R.E.S.; BRAGA, F.G. Migração e rede urbana: procedências e inserção ocupacional. In: ENCONTRO NACIONAL DE ESTUDOS POPULACIONAIS, 13, 2002, Ouro Preto. Anais. 2002.

MUKKALA, K. Knowledge spillovers - mobility of highly educated workers within high technology sector in Finland. Congress of the European Regional Science Association, 45, Amsterdam, Holanda. Agost., 2005.

NAKOSTEEN, R.A.; WESTERLUND, O. The effects of regional migration on gross income of labour in Sweden. Regional Science, v. 83, p. 581-595, 2004.

NETTO JUNIOR, J.L.S.; MOREIRA, I.T. Migrações e diferenciais de renda estaduais: uma análise por dados em painel no período de 1950-2000. In: ENCONTRO TRANSDISCIPLINAR ESPAÇO E POPULAÇÃO. Anais. Campinas. 2003. 
OLIVEIRA, K.F.; JANNUZI, P.M. "Motivos para migração no Brasil e retorno ao nordeste: padrões etários, por sexo e origem/destino". São Paulo em Perspectiva, v. 19, n. 4, p. 134-143, dez. 2005.

PEKKALA, S. "Migration flows in Finland: regional differences in migration determinants and migrant types”. International Regional Science Review, v. 26, n. 4, p. 466-482, 2003.

QUEIROZ, B.L., GOLGHER, A.B. "Human capital differentials across municipalities and states in Brazil” (Texto para discussão: 330). Belo Horizonte: CEDEPLAR, 2008. 27p.

RIGOTTI, J.I.R. "Geography of population flow according to the migrants educational level”. Estudos avançados, São Paulo, v. 20, n. 57, p. 237-254, 2006.

SJAASTAD, L.A. “The costs and returns of human migration”. Journal of Political Economy, v. 70, n. 5, p. 80-93, 1962.

STAMBOL, L.S. Urban and regional labour mobility performance in Norway. Congress of the European Science Association, 43. Finlândia, 2003.

VISZT, E. et al. Mobility of Human Resources in Hungary: An Analysis and a Proposal for Regular Collection of Statistics. In: OECD (Org). Innovative people: mobility of skilled personnel in national innovation systems. 2001. p. 175-188.

ZIMMERMANN, K.F. European labour mobility: challenges and potentials. Berlin: University of Bonn and DIW, 2004. 


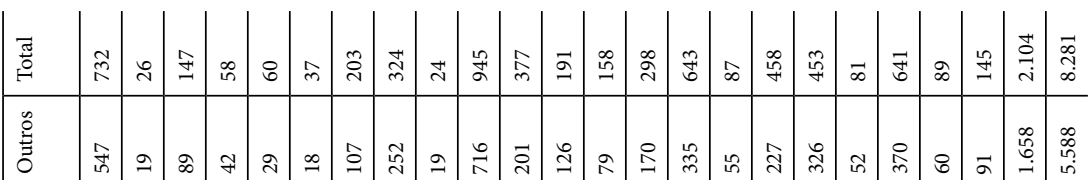

岂 乡

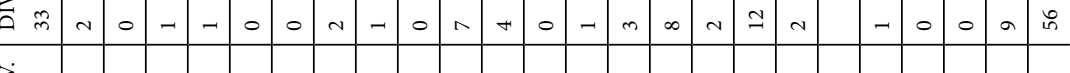

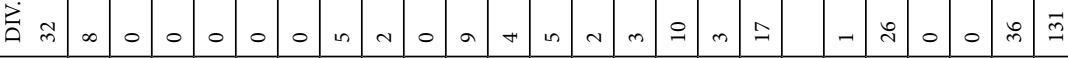

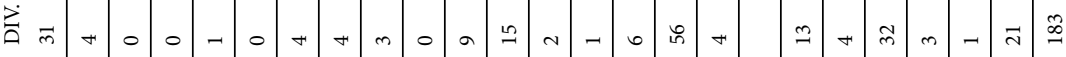

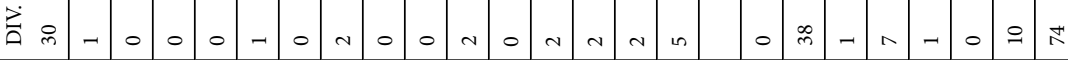

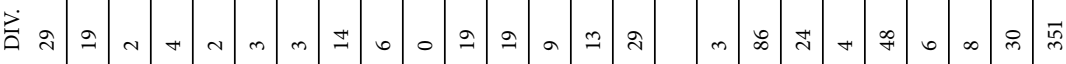

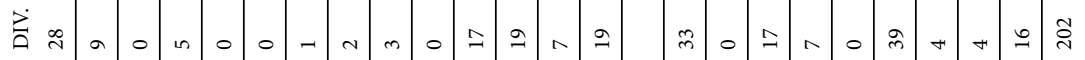

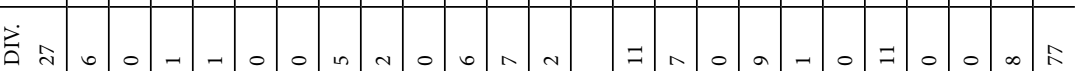

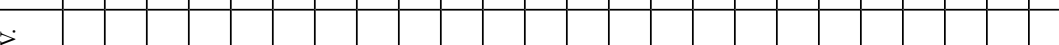

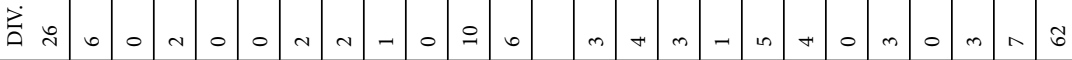

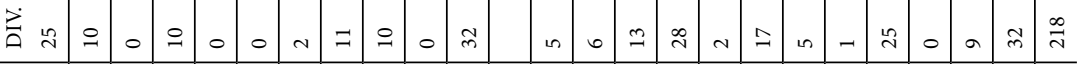

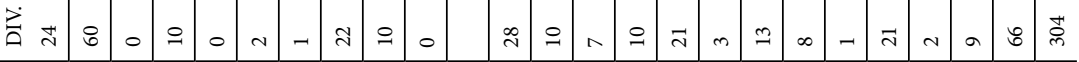

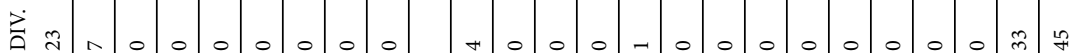
芫

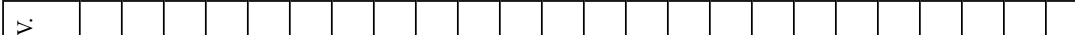

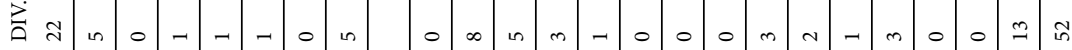

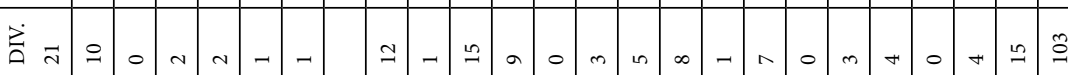

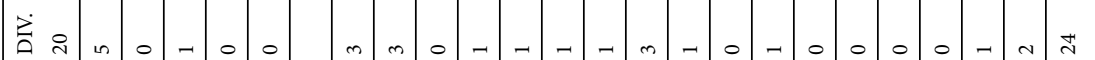

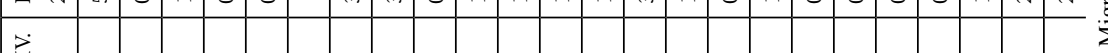

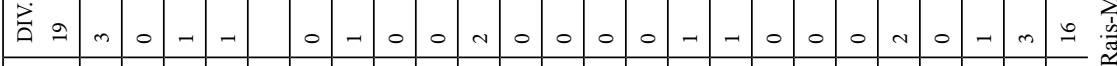

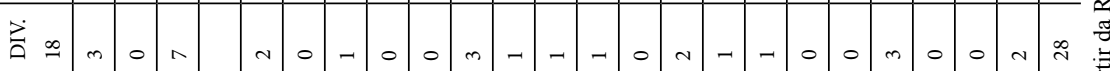

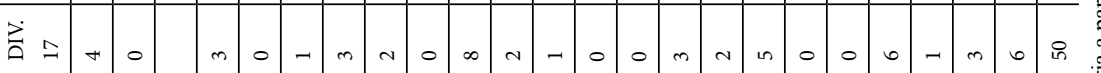

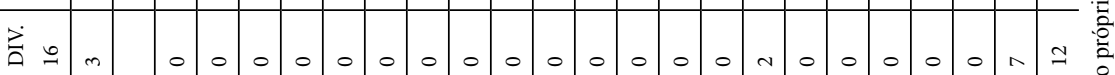

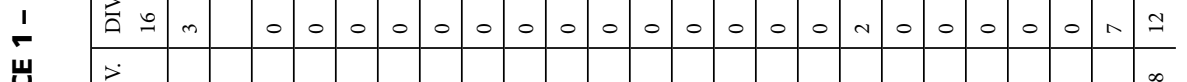

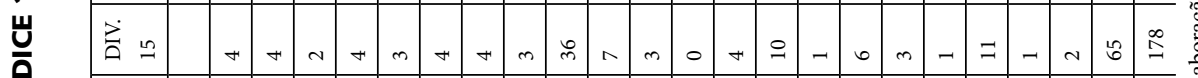
苟

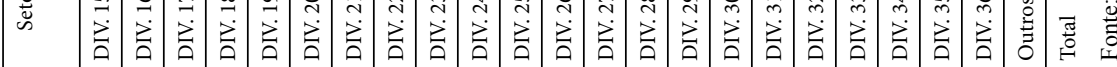

